\title{
Educação estatística - uma proposta de ensino
}

\author{
Statistics education - a teaching approach
}

\author{
Simone Regina dos Reis', Ivanor Müller", \\ Fernando de Jesus Moreira Junior'I", Angela Pelegrin Ansuj'v
}

\begin{abstract}
RESUMO
Ciente do compromisso de estimular o aluno a aprender Estatística, o presente trabalho desenvolveu um estudo sobre o desenvolvimento da Educação Estatística nas escolas, descrevendo o estado da arte da educação estatística, assim como estabelecer relações com diferentes áreas do conhecimento, com vistas a destacar a importância do ensino da estatística que considere o seu papel na vida dos estudantes e proporcione um espaço pedagógico que valorize o processo ao invés do fato, as idéias ao invés das técnicas. Esta pesquisa visa propor diversidade de problemas envolvendo outras áreas ou mesmo áreas internas à própria Matemática, a fim de relevar a importância da Estatística na formação de cidadãos, consumidores de informações veiculadas pela mídia, ou como profissionais que lidam com informações estatísticas, ou enquanto pesquisadores, que lidam com a metodologia científica. Os resultados desta pesquisa apontam que é importante que o professor aprenda conhecer a realidade dos alunos, de modo que possa intervir considerando: a) as múltiplas relações envolvidas nas diferentes situações com que se depara ao participar do processo de aprendizagem e; b) os contextos socioculturais dos alunos.
\end{abstract}

Palavras-chaves: Ensino, Educação Estatística, Formação Social.

\section{ABSTRACT}

Aiming to improve it, the statitics 'pedagogical practice has been investigated in order to find out a cientifical methological way to help the practice of teaching and its application in the classroom. This work tries to develop a research about statistics education in schools, asking teachers and students in relation to the importance of developing a significative mathematic, in which its role is essencial in student's life. The purpose of this research is to offer some interdisciplinary problems to be solve in order to come out with the importance of considering the statitics 'user attitudes, trying to emphasis that the mathematics as well as the statics has been present in student's life, for example, as long as students are citizen getting media information's as well as statistics professionals - who work with statistics' information as well as researchers - who work with scientific methodologies. the results suggests that it is important to consider that teachers should know student's reality in order to interfere taking in consideration: a) the relations' diversity involved in different situations in which the teacher takes part to participate in the process of teaching and learning and; b) the social cultural contexts in which students participate.

Key-words: Teaching, Statistics Education, Social Formation.

\footnotetext{
'Universidade Federal de Santa Maria, Brasil; e-mail: simone_reis@msn.com;

" Universidade Federal de Santa Maria. Brasil. e-mail: ivanormuller@smail.ufsm.br;

I' Universidade Federal de Santa Maria, Brasil; e-mail: fmjunior777@yahoo.com.br

Iv Universidade Federal de Santa Maria, Brasil; e-mail: angelaansuj@yahoo.com
} 


\section{INTRODUÇÃO}

Manter-se atualizado sobre as novas metodologias de ensino e desenvolver práticas pedagógicas mais eficientes são alguns dos principais desafios da profissão de educador. Uma das principais preocupações da educação é a maneira pela qual os alunos aprendem, o que requer dos educadores uma aproximação com outras áreas das ciências do comportamento.

Como afirma Bassanezi (1985), “o ensino deve estar voltado para os interesses e necessidades da comunidade e sob este ângulo cada aluno deve participar efetivamente do desenvolvimento de cada conteúdo e do curso como um todo". Desse modo, é muito importante que o professor aprenda a conhecer a realidade para além das aparências, de modo que possa intervir considerando as múltiplas relações envolvidas nas diferentes situações com que se depara referente aos processos de aprendizagem e aos contextos socioculturais dos alunos. Assim, ao perceber que a Estatística, a Matemática e a Educação manifestam uma relação reciprocamente dependente, origina-se a Educação Estatística que centraliza seus objetivos no desenvolvimento do pensamento probabilístico e estatístico. Isto ocorre devido à problemática constatada em sua real aprendizagem e da necessidade de esclarecimento de sua aplicabilidade às mais diversas áreas de conhecimento.

Cientes do compromisso de estimular o aluno em relação à Estatística, o presente trabalho visa desenvolver um estudo sobre o desenvolvimento da Educação Estatística nas escolas, questionando professores e alunos sobre a importância, aplicação e desenvolvimento desta na Educação Fundamental e Média. Assim, buscase estabelecer relações com as diferentes áreas do conhecimento de modo que, os alunos possam identificar a importância da Estatística na formação de cidadãos: consumidores, profissionais e pesquisadores.

Justifica-se este trabalho pela importância da Estatística na formação do cidadão, na medida em que este fica exposto a informações Estatísticas veiculadas pela mídia. Essas informações podem influenciar na tomada de decisões que, muitas vezes, pela ausência de conhecimento na área, são consumidas sem uma filtragem, tornando o cidadão vulnerável a interpretações que não correspondem à realidade. 


\section{A IMPORTÂNCIA DA EDUCAÇÃO ESTATÍSTICA}

Segundo os Parâmetros Curriculares Nacionais (PCNs), à medida que o cidadão se integra em uma sociedade de informação e crescentemente globalizada, as capacidades de comunicação, de solucionar problemas, de tomar decisões, de fazer inferências, de criar, de aperfeiçoar conhecimentos e valores, de trabalhar cooperativamente, são cada vez mais exigidas. A competência em Matemática e a possibilidade de compreender conceitos e procedimentos matemáticos são necessárias aos sujeitos tanto para que eles tirem conclusões e façam argumentações, quanto para agir como consumidores prudentes ou para tomar decisões em suas vidas pessoais e profissionais.

Até a implantação dos PCNs, o ensino de Estatística no nível fundamental e médio era muito restrito e marginal. Hoje esse quadro mudou pelo destaque especial dado a estatística e probabilidade, que estão inseridas no volume III (Matemática) dos PCNs. Sem dúvida, a proposta dos PCNs se constitui num grande avanço para o ensino de Estatística no ensino fundamental e médio.

Desse modo a Educação Estatística pode ser definida como uma área de pesquisa, cujo objeto de estudo seria os fatores que interferem no processo ensinoaprendizagem de Estatística buscando o desenvolvimento das habilidades de solução para problemas e análise de dados, e assim, possibilitando o desenvolvimento do pensamento estatístico. A Educação Estatística deverá pesquisar desde a aprendizagem à capacidade cognitiva dos alunos, o papel dos aspectos afetivos na aprendizagem e na aplicação da estatística, o desenvolvimento de métodos e materiais de ensino, além da epistemologia dos conceitos estatísticos.

Seria importante observar que o ensino da Estatística não poderia vincular-se a uma definição de Estatística restrita e limitada, isto é, a uma simples coleta, organização e representação de dados, pois este tipo de trabalho não viabilizaria a formação de um aluno com pensamento e postura críticos. (LOPES, 1998, p. 115). Segundo Carzola (2002) a análise exploratória de dados foi trazida para a sala de aula nos anos 70 por Tukey (1977) e, no início do século XXI, já era considerada como a forma ideal de ensinar e aprender estatística (Scheaffer, 2000). No entanto, continua a não ser uma presença 
em muitas das salas de aula (Fonseca \& Ponte, 2000; Lopes, 1998). Ela ainda ressalva que Scheaffer $(1990,2000)$ refere às seguintes vantagens para a introdução da análise exploratória de dados, mesmo no que se refere à aprendizagem dos conceitos elementares, "não só porque é a forma mais fácil de fazê-lo, mais motivadora e a mais criativa para além de que é a forma como muitas investigações científicas começam" (SCHEAFFER, 1990, p. 93).

Só assim os alunos compreendem como a recolha, a organização e a interpretação acontecem ao mesmo tempo em que descobrem capacidades de argumentar, refletir, criticar, sem esquecer as competências ligadas aos próprios conceitos estatísticos; referindo-se ao fato de que não estando ativamente envolvidos na criação dos dados, facilmente apresentam dificuldades em analisá-los, ou mesmo, em saber como devem fazê-lo. Assim a alfabetização Estatística se torna a habilidade para entender e avaliar criticamente resultados que permeiam nossas vidas, conjugada com a habilidade para apreciar contribuições que o pensamento estatístico pode fazer nas decisões pública e privada, profissional e pessoal (WALLMAN, 1993, p.1).

É necessário educar o consumidor para entender melhor a Estatística. A alfabetização Estatística deve ser acrescentada ao leque de habilidades do cidadão. Isso implica, também, na educação dos próprios educadores, para que estes possam entender melhor o que os consumidores de outras ciências querem e precisam, direcionando suas ações de acordo com essa demanda. Sendo assim, os educadores estatísticos devem ser capazes de avaliar a situação dos alunos no seu interesse ou motivação para aprender mais, no auto-conceito ou confiança em relação às habilidades estatísticas, na capacidade para pensar estatisticamente em situações cotidianas e na valorização da estatística na vida pessoal e profissional.

\section{EDUCAÇÃO ESTATÍSTICA - UMA PROPOSTA DE ENSINO}

O ensino de Probabilidade e Estatística faz parte do currículo do ensino fundamental e médio, e está inserido nos PCNs. Contudo, nem todos os alunos que ingressam nas universidades passaram por um ensino de Estatística e Probabilidades sistematizado durante sua formação escolar, e chegam à universidade, sem saber o que é a Estatística, seu importante papel na tomada de decisões em condições de 
incerteza, que ela representa uma parte substancial da metodologia científica, e quase sempre a confunde com a matemática. Nesse contexto, foi realizado um teste piloto, com 16 alunos do ensino fundamental de escolas públicas e particulares de Santa Maria. Eram alunos de $8^{\mathrm{a}}$ série, com idade média de 14 anos. Eram alunos de classe média que tinham acesso a computadores, internet, jornais e revistas em suas próprias casas.

A proposta apresentou 3 etapas: um questionário, uma prova de interpretação de gráficos e uma atividade de modelagem matemática, que envolvia gráficos e funções. A aplicação do questionário visava avaliar os conhecimentos matemáticos, gráficos e perceptivos destas disciplinas no mundo real. A prova de interpretação de gráficos visava apresentar a estatística em diferentes contextos e analisar o conhecimento dos alunos em situações do dia-a-dia.

Após ser aplicado o questionário e a prova de conhecimentos, foi sugerido o seguinte exercício: "Forme grupos de 2 ou 3 alunos. Escolha um dentre os temas de pesquisa: As alturas dos alunos; O tipo de música preferida; Os atores ou atrizes preferidos; A maior preocupação de cada aluno da classe; A evolução das notas em cada bimestre; O maior problema da cidade (bairro) na opinião de cada um; O esporte preferido. Os números de cada pesquisa devem ser organizados em tabelas, calculando-se também os percentuais. Como os resultados dificilmente serão exatos, convém usar calculadora. Depois, as tabelas devem ser transformadas em gráficos (escolha o tipo de gráfico mais conveniente para cada situação)".

Como o objetivo da pesquisa é conscientizar educadores matemáticos para a inserção da estatística nos próprios conteúdos matemáticos e, em qualquer área de conhecimento, na busca pela prática de um ensino que oportunize a percepção dos conhecimentos matemáticos e estatísticos como ferramenta para diferentes situações do cotidiano e, consequentemente, para a contemplação do interesse e da participação dos alunos, justifica-se a modelagem matemática como metodologia de ensino. Biembengut (1997, p. 89), em sua tese de doutorado, define modelação matemática como $\{. .$.$\} um método que usa a essência da modelagem matemática para ensinar, em$ cursos que tem o programa (currículo) predeterminado. Ainda afirma que, este método 
diferencia-se da modelagem no ensino, pois utiliza um único tema para extrair o conteúdo programático. Para a modelação Matemática, o mais importante não é a obtenção do modelo, mas o caminhar pelas etapas de onde vão emergindo os conteúdos matemáticos.

Segundo Biembengut (1997), o método abrange três momentos:

1) justificativa do processo

Nesse momento, o professor justifica o processo, expondo o interesse no processo de aprendizagem e procurando motivar os alunos para que voluntariamente decidam por um desenvolvimento ativo do aprendizado, tornando-se co-responsáveis pelo ensino-aprendizagem.

2) escolha do tema

O professor e aluno devem sugerir temas. Contudo, caberá ao professor usar estratégias que facilitem aos alunos a escolha de um tema abrangente, motivador e sobre o qual, de certa maneira, seja fácil obterem-se dados e informações.

3) desenvolvimento do conteúdo

Esta fase é semelhante à do curso de modelagem, não esquecendo que agora existe um conteúdo programático e cabe ao professor fazê-lo fluir a partir do tema. Para que isso ocorra, o professor pode fazer a primeira questão ou propor aos alunos que dêem sugestões do que se possa estudar, ou ainda propor que os próprios levantem questões. Desta forma, o professor poderá levantar a situação mais adequada para desenvolver o conteúdo programático.

O exercício proposto era muito simples, mas exigia organização e discussão em grupo. Depois de definido os grupos foram coletados os dados de todas as perguntas e distribuído entre os grupos. Depois de discutido os tipos de gráficos conhecidos, cada grupo ficou encarregado de organizar os dados, efetuar os cálculos necessários e definir o gráfico adequado. Todos perceberam, por exemplo, que as alturas deveriam ser representadas em um histograma e o tipo de música em um gráfico de setores. Cabe lembrar que esses alunos, ainda que muito precariamente, já haviam tido durante 
seu ensino fundamental uma noção de estatística. Cabe salientar que esta pesquisa se tornará base para pesquisas posteriores uma vez que, foram trabalhados apenas conceitos estatísticos e, em pesquisas posteriores deseja-se trabalhar a educação estatística por meio da modelagem matemática para a consciência da ação política envolvida em sua prática pedagógica.

Para que o ensino da estatística possa contribuir para a efetivação desse fato, talvez se deva desenvolver uma matemática significativa, na qual se considere seu papel na vida dos estudantes, que proponha uma grande diversidade de problemas envolvendo outras áreas ou mesmo áreas internas à própria matemática. É importante que alunos sejam expostos a problemas variados do mundo real e que tenham possibilidades de escolherem suas próprias estratégias para solucioná-los. Assim, é possível desenvolver uma atitude de respeito aos saberes que o estudante traz à escola, adquiridos em seu meio cultural, envolvendo a discussão de temas como; a poluição dos rios e mares, os baixos níveis de bem-estar das populações, o abandono da saúde pública, as políticas assistenciais, greves, desemprego, entre outras.

\section{ANÁLISE E DISCUSSÃO DOS RESULTADOS}

Com o objetivo de identificar o conhecimento dos alunos em Estatística, foi realizado um questionário com questões relativas à definição de estatística (Tabela 1), conhecimento de gráficos (Tabela 2) e percepção de conceitos matemáticos além da escola (Tabela 3).

Tabela 1 - Definição de Estatística.

\begin{tabular}{lcc}
\hline O que é Estatística? & Sujeitos & $\%$ \\
\hline$>$ Matemática: números, porcentagens, cálculos, problemas algébricos. & - & - \\
$>$ Análise de dados: comparação, análise de dados. & 6 & 37,50 \\
$>$ Organização de dados: tabelas, gráficos, médias, desvio padrão. & 6 & 37,50 \\
$>$ Coleta de dados: dados, informações, mensuração de dados. & 2 & 12,50 \\
$>$ Estatística descritiva: coleta, organização e análise de dados. & 2 & 12,50 \\
\hline Total & 16 & 100,00 \\
\hline
\end{tabular}

Os resultados da Tabela 1 eram, em parte, esperados, uma vez que, a maioria dos alunos não teve uma aula de Estatística, apesar de que deveriam ter noções bem melhores dos conceitos elementares. Do mesmo modo, para analisar o conhecimento 
gráfico anterior que os sujeitos acreditavam possuir, foi apresentada uma questão, contendo quatro tipos de gráficos e foi solicitado ao aluno que indicasse qual desses gráficos conhecia, já teria estudado ou já havia visto. Conforme a Tabela 2, os gráficos mais conhecidos pelos alunos são o de colunas ou barras e o circular ou de setores.

Tabela 2- Estudo de Gráficos.

\begin{tabular}{lll}
\hline $\begin{array}{l}\text { Tipos de Gráficos que você: conhece, já estudou, já } \\
\text { desenhou a mão, já desenhou no computador, Etc. }\end{array}$ & $\%$ \\
\hline$>$ Colunas ou barras & 5 & 31,25 \\
$>$ Circular (de setores) & 5 & 31,25 \\
$>$ Linhas & 3 & 18,75 \\
$>$ Outros & 3 & 18,75 \\
\hline TOTAL & 16 & 100,00 \\
\hline
\end{tabular}

Com o objetivo de avaliar o conhecimento matemático dos alunos, na sua aplicação diária, foi solicitado a eles que indicassem em quais ocasiões percebiam conceitos matemáticos além da escola. Conforme a Tabela 3, percebe-se que $50 \%$ dos alunos percebem os conceitos de matemática em supermercados ou lojas.

Tabela 3 - Percepção de Conceitos Matemáticos.

\begin{tabular}{lll}
\hline Você já percebeu conceitos matemáticos além da escola? & Sujeitos & $\%$ \\
\hline$>$ Supermercado, lojas. & 8 & 50 \\
$>$ Em revistas, jornais. & 6 & 37,5 \\
$>$ Nunca & 1 & 6,25 \\
$>$ Matemática é aplicável? & 1 & 6,25 \\
\hline TOTAL & 16 & 100 \\
\hline
\end{tabular}

Considerando a interdisciplinaridade da Estatística, foi apresentada uma prova de gráficos composta por quatro questões. No primeiro problema (Figura 1), o gráfico de setores, ilustrava a relação entre a quantia gasta em cada área e a arrecadação total de dois estados em um determinado país. A partir do gráfico apresentava-se duas perguntas. 
Figura 1 - Questão 1

1. (PROVÃO DE MATEMÁTICA) Numa prova, o professor apresenta a seguinte questão: dois estados do país, num certo ano, apresentam o modo como dividiram os impostos arrecadados. Os gráficos de setores a seguir ilustram a relação entre a quantia gasta em cada área e a arrecadação total daquele estado naquele ano.
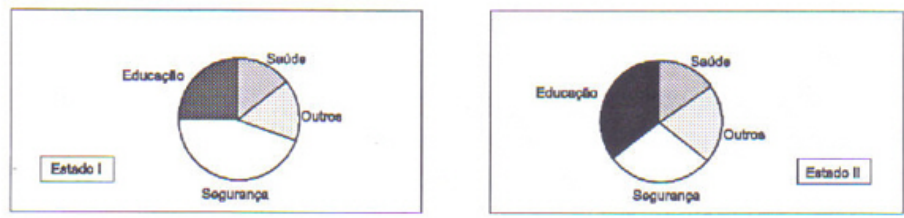

I)Determine que percentual da arrecadação do estado II, daquele ano, foi gasto com saúde e educação, juntas. Justifique.

II) Pode-se dizer que naquele ano o estado I gastou mais com segurança do que o estado II? Por quê?

A primeira pergunta exigia uma leitura no nível elementar, requerendo apenas a extração de informação já existente no gráfico. Referia-se ao percentual da arrecadação do estado II na área de saúde e educação, naquele ano, com justificativa. Observa-se que praticamente todos os alunos $(87,50 \%)$ conseguiram identificar que a arrecadação do estado II com saúde e educação, correspondia a 50,00\% do total de arrecadação naquele ano. Também justificaram corretamente que representava a metade da circunferência. Já a segunda pergunta ofereceu muita dificuldade, pois ninguém conseguiu responder corretamente. Essa tarefa consistia em comparar os gráficos num determinado item (segurança) e analisar se o estado I havia gastado mais que o estado II justificando a resposta. Como já era esperado 75\% respondeu que sim porque a área representada pela segurança no gráfico do estado I era maior do que no gráfico II, sendo que não era possível informar qual estado havia gastado mais, pois não temos no gráfico a informação do investimento total de cada um.

O segundo problema (Figura 2) referia-se a um gráfico de colunas, utilizado para avaliar os níveis de audiência de alguns canais de televisão entre $20 \mathrm{~h}$ e $21 \mathrm{~h}$ de uma determinada noite. A questão era de múltipla escolha e pedia a porcentagem aproximada de entrevistas que declaravam estar assistindo a um dos canais (TvB). A tarefa exigia além da leitura cuidadosa do gráfico, o domínio de porcentagem. A maioria dos alunos $(68,75 \%)$ apenas identificou no gráfico a altura relativa à coluna correspondente a TVB, ou seja, considerou a porcentagem de entrevistas em aproximadamente $30 \%$. Somente $(18,75 \%)$ resolveram o exercício corretamente, uma 
vez que considerada a porcentagem relativa à coluna da TvB deveria ser calculada a razão entre a porcentagem da TvB pelo somatório das porcentagens das colunas relativas aos outros canais de televisão.

Figura 2 - Questão 2

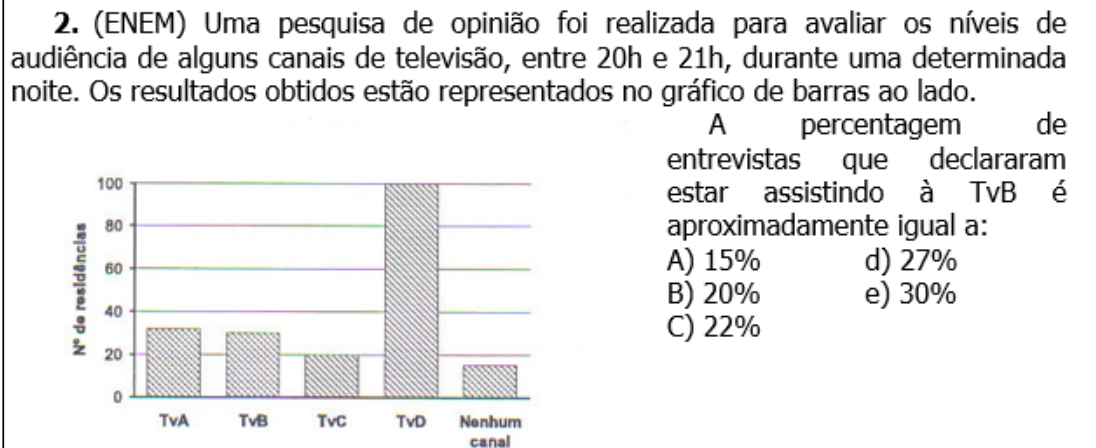

O terceiro problema (Figura 3) referia-se a um gráfico de colunas justapostas, que comparava o número de homicídios por grupo de 100.000 habitantes entre 1995 e 1998 nos EUA, em estados com e sem pena de morte. Baseados no gráfico, os alunos deveriam avaliar se a taxa de homicídios era maior ou menor nos estados com pena de morte ou nos estados sem pena de morte. O exercício era de nível elementar, portanto a maioria (62,50\%) identificou a alternativa correta que, a partir da interpretação do gráfico podia-se concluir que os estados com pena de morte, no período entre 1995 e 1998, apresentavam maiores taxas de homicídios.

Figura 3 - Questão 3

3. (ENEM) o gráfico compara o número de homicídios por grupo de 100.000 habitantes entre 1995 e 1998 nos EUA, em estados com e sem pena de morte.

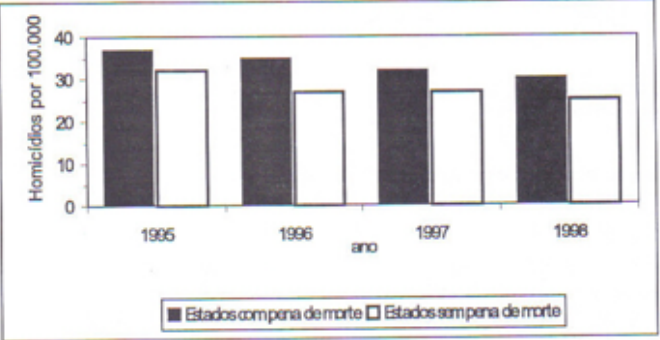

apresentaram taxas maiores de homicídios.

D) Entre 1996 e 1997, a taxa de homicídios permaneceu estável nos estados com pena de morte.

E) A taxa de homicídios nos estados com pena de morte caiu pela metade no período considerado. afirmar que.

A) A taxa de homicídios cresceu apenas nos estados sem pena de morte.

B) Nos estados com pena de morte a taxa de homicídios é menor que nos estados sem pena de morte.

C) No período considerado, os estados com pena de morte

Com base no gráfico, pode-se 
O último problema apresentava um gráfico de colunas, ilustrando um hemograma, ou seja, um exame laboratorial que informa o número de hemácias, glóbulos brancos e plaquetas presente no sangue. Havia uma tabela informando os valores considerados normais para um adulto e, três gráficos que representavam esses elementos no sangue de cinco alunos. A questão era de múltipla escolha e perguntava se ocorria deficiência no sistema de defesa do organismo, prejuízos no transporte de gases respiratórios e alterações no processo de coagulação sanguínea em algum dos estudantes.

Figura 4 - Questão 4

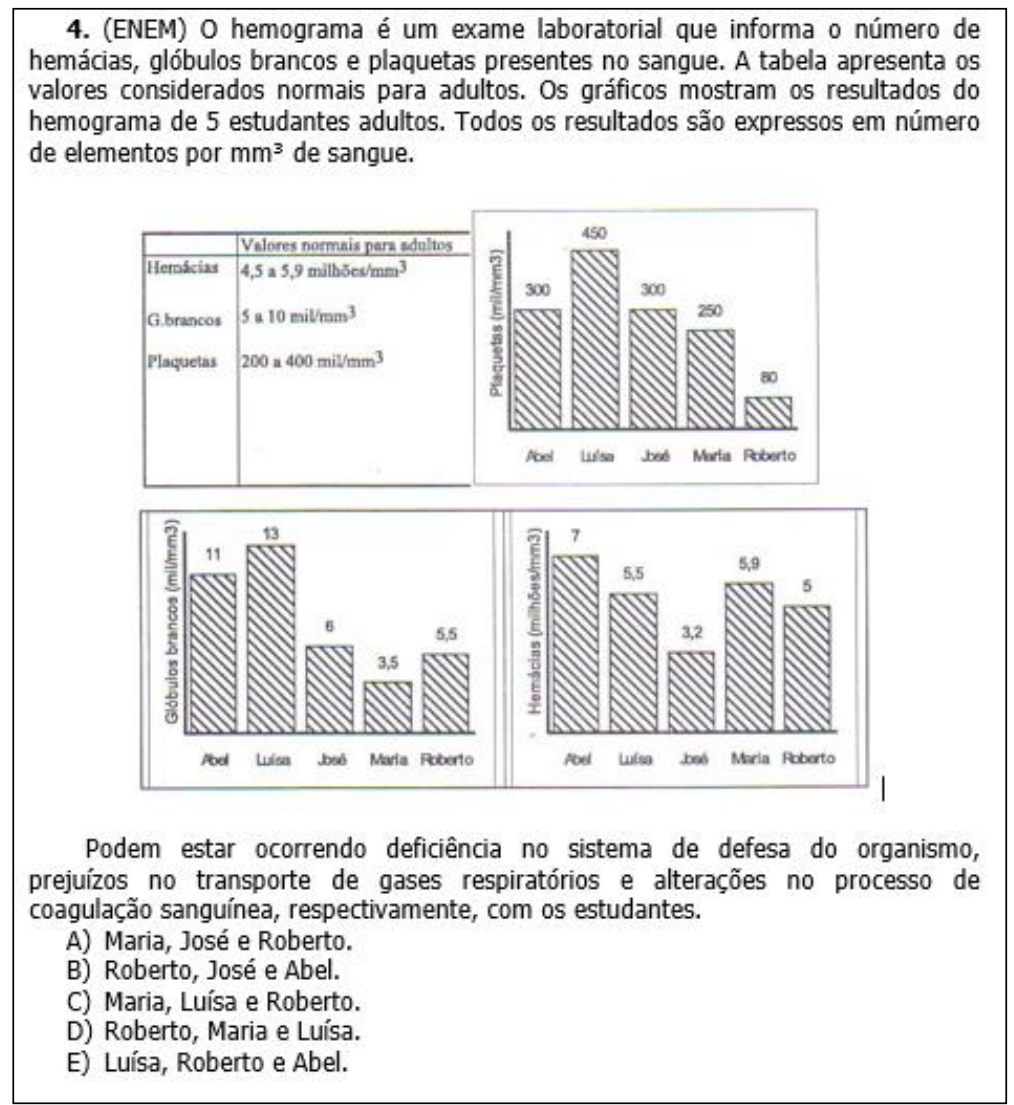

A questão era considerada difícil, pois associada à interpretação dos gráficos estavam domínios de conceitos de biologia visando à interdisciplinaridade da estatística. O resultado foi interessante, pois $50 \%$ dos alunos marcaram a alternativa correta. Para responder ao exercício, era necessário saber que o sistema de defesa do organismo, o funcionamento do transporte de gases respiratórios e o processo de coagulação sanguínea estão associados, respectivamente, as dosagens de glóbulos brancos, hemácias e plaquetas. Assim, quem tem deficiências no sistema de defesa é 
Maria, quem tem uma dosagem muito baixa de glóbulos brancos. Quem tem quantidade de hemácias abaixo do normal é José. Já quem tem baixa dosagem de plaquetas é Roberto.

Essas são questões presentes diariamente em jornais, reportagens de televisão ou manchetes de revistas. É claro que o nível do aprofundamento de cada uma delas deve sempre considerar e respeitar a faixa etária na qual se está desenvolvendo o estudo. São possíveis que estes sejam os primeiros momentos do exercício de reflexão para que possamos estar viabilizando a formação de cidadãos críticos, éticos e reflexivos.

\section{CONCLUSÃO}

Ao considera-se o mundo em rápida mudança, um mundo de informações, uma sociedade do conhecimento, é imprescindível o conhecimento da estatística para a tomada de decisão e fazer previsões. Da mesma forma que se torna cada vez mais precoce o acesso do cidadão a questões sociais e econômicas nos quais tabelas e gráficas sintetizam levantamentos; índices são comparados e analisados para defender idéias.

Considera-se relevante que o ensino da estatística faça parte do currículo de matemática no ensino fundamental e médio, pois possibilita ao estudante desenvolver a capacidade de coletar, organizar, interpretar e comparar dados para obter e fundamentar conclusões, que são à base do desempenho de uma atitude científica. Tanto alunos como professores devem de fato pensar e refletir criticamente sobre os conceitos estatísticos e probabilísticos e, não simplesmente utilizá-los como ferramenta de forma mecânica e alienada. É papel de a escola proporcionar ao estudante a formação de conceitos estatísticos e probabilísticos que o auxiliarão no exercício de sua cidadania. Pois, ao cidadão não basta entender as porcentagens expostas em índices estatísticos, como o crescimento populacional, taxas de inflação, desemprego, entre outras. É preciso que ele saiba analisar e relacionar criticamente os dados apresentados, questionando e ponderando, inclusive, sua veracidade. Assim como não é suficiente ao aluno desenvolver a capacidade de organizar e representar uma coleção de dados, faz-se necessário interpretar e comparar esses dados para tirar 
conclusões. Pensar a inserção dessas temáticas na educação é considerar um processo centrado na reflexão e na criatividade, rompendo com o determinismo que predomina nos currículos dessa disciplina, e mais propriamente com o pensamento determinista, inibidor da idéia de movimento e transformação.

Nesse cenário, a matemática tem se justificado pelas necessidades das próprias crianças de construírem e recriarem conhecimentos, desenvolverem a imaginação e a criatividade, bem como, por uma necessidade social de instrumentalizá-las para a vida no mundo. Cada vez mais, e mais rapidamente, tem-se exigido diferenciadas habilidades e competências matemáticas dos cidadãos. Nesse sentido, acredita-se que o desenvolvimento do pensamento estatístico e probabilístico, que deve ser inserido no contexto escolar, possa apresentar significativas contribuições para a formação das crianças.

A realização de experimentos que envolvem a aleatoriedade e estimativas, bem como, a vivência de coletar, representar e a analisar dados que sejam significativos e inseridos no seu contexto podem ampliar o universo de competências e acentuar o potencial criativo dos alunos. Nessa perspectiva de ensino, é possível promover uma formação que os alunos pensem mais amplamente a respeito de diferentes questões e estabeleçam adequadamente estratégias e técnicas para solucionar problemas que permeiam sua vida.

O trabalho com estatística em sala de aula deverá promover discussões e reflexões para a solução de uma situação-problema que seja levantada pela classe ou instigada pelo professor. Este deverá promover, a todo o momento, o debate, mantendo aberto o "canal de diálogo" com os alunos. Tais posturas são fundamentais para desenvolver a atitude democrática por meio da educação matemática. Acreditase que, para desenvolver o ensino da estatística, o professor precisará, além de atualizar e construir seus próprios conhecimentos sobre o tema, refletir sobre o quanto ele se opõe ao determinismo, ao mesmo tempo em que poderá visualizar o fato de que vivemos em um mundo que é simultaneamente aleatório e determinista. Espera-se que esse trabalho venha contribuir para superar as dificuldades encontradas pelos professores, no que diz respeito ao processo de ensino-aprendizagem da estatística. 


\section{REFERÊNCIAS}

BASSANEZI, C. R. Modelagem como metodologia de ensino de matemática. IMECC: Unicamp, 1985.

BIEMBENGUT, M. S. Qualidade de ensino de matemática na Engenharia: uma proposta metodológica e curricular. Tese de doutorado, Curso de Pós-graduação em engenharia de produção e sistemas. Florianopolis: UFESC, 1997.

CAZORLA, I.M. A relação entre a habilidade viso-pictórica e o domínio de conceitos estatísticos na leitura de gráficos. Tese de doutorado, Unicamp: Campinas, SP, 2002.

LOPES, C. A. A probabilidade e a educação no ensino fundamental: uma análise curricular. Dissertação de mestrado. Campinas: FE/Unicamp, 1998.

MEC. Parâmetros Curriculares Nacionais: Matemática. Secretaria de Educação Fundamental - Brasília: MEC / SEF, vol. 13, 1998.

SCHEAFFER, R. Statistics for a new century. In m. J. Burke \& f. R. Curcio (eds.), learning mathematics for a new century (pp. 158-173). Reston: NCTM, 2000.

WALLMANN, K. K. Enhancing statistical literacy: enriching our society. Journal of the American statistical association, 88 (421), 1-8, 1993. 